\title{
Chemotherapy Treatment and Strategy Schemes: A Review
} \author{
Naik $^{4}$, BD Tripathi ${ }^{1}$ and KL Dhar ${ }^{5}$ \\ ${ }^{1}$ Narayan Institute of Pharmacy, India \\ ${ }^{2}$ Faculty of Dentistry, Taif University, Saudi Arabia \\ ${ }^{3}$ Govt Pharmacy Institute, India \\ ${ }^{4}$ Nandha College of Pharmacy, India \\ ${ }^{5}$ Faculty of Pharmaceutical Sciences, Shoolini University, India
}

Afroze Alam ${ }^{1,5 *}$, U Farooq ${ }^{2}$, Ruchi Singh ${ }^{1}$, VP Dubey ${ }^{1}$, Shailendra Kumar ${ }^{3}$, Rashmi Kumari ${ }^{1}$, Kamlesh Kumar

Submission: November 03, 2017; Published: March 29, 2018

*Corresponding author: Afroze Alam, Narayan Institute of Pharmacy, Bihar, India, Tel: +91-8091974886; +91-7018196843; Fax: +91-1792308000; Email: afrozepharma@gmail.com; afrozalam@niop.in

\begin{abstract}
Chemotherapy treatments are used to inhibit vigorously growing malignant cells with anticancer agents. This type of therapy may be used to cure and try a patient to produce palliative relief and symptomatic relaxation in the advance stages of cancer. In general, chemotherapy is given in cyclic manners. Patients are administered with anticancer drug during regular weekly or bi-weekly sessions. After the completion of certain cyclic session, treatment is stopped for several fixed periods to allow the patient to rest and their body to re-establish from the toxic effects of anticancer drugs. Generally, six or more chemotherapeutic cycles are needed in cancer patient and often a combined chemotherapy would be preferred. Anticancer drugs are used to destroy not only to specific cancer cell but equally affect the normal cell that developing under normal circumstances, such as those in the digestive tract, bone marrow and hair follicles. Combination chemotherapy is always preferred over traditional therapies, such as radiotherapy, surgery or other cytotoxic drugs. The mechanism of action of each therapy is different for inhibiting cell division and proliferation of rapidly growing cell. Each treatment has their specific side effects. A large numbers of treatment strategy are available to fight with cancer, depending upon the severity and stage of cancer, type of cancer, and the affected body parts. The review describes the alternative methods that combine chemotherapy with other treatment strategies have been explored in order to improve treatment selectivity, reduce recurrence and improve the quality of life of patients.
\end{abstract}

Keywords: Chemotherapy; Cytotoxic agents; Radiotherapy; Non-pharmacological treatment; Cell proliferation; Hypertheramia

\section{Introduction}

Chemotherapy literally means the use of chemicals in order to inhibit malignant cell or to the infectious agents of a disease such as micro-organism without much affecting the host cells [1]. Therefore, the treatment can be broadly divided into two categories - cancer chemotherapy and antimicrobial chemotherapy. The drugs belong to these categories, are different from the others as they are generally intended to kill or inhibit the target organism and have no or minimal effect on host cell [2]. Earlier, it was considered that the chemotherapeutic agents were restricted to synthetic compounds but, now a day many more natural products are marketed as potential chemotherapeutic agents or antibiotics. The present status demands that both the synthetically as well as naturally or microbiologically produced drugs need to be included together. In traditional chemotherapy, all the anticancer drugs are cytotoxic in nature to both cancer as well as normal cells [3], meaning thereby is that chemotherapy also destroy cells that divide rapidly under normal circumstances: digestive tract, cell in bone marrow and hair follicles. There is a most common side effects observed during the period of chemotherapy treatment: mucositis (inflammation of the lining of the digestive tract), alopecia (hair loss) and myelosuppression (decreased production of blood cells, hence also immunosuppression) [4]. Most of the monoclonal antibodies are not indiscriminately cytotoxic and act by targeting proteins that are over expressed in cancer cells and essential for their proliferation [5]. This kind of treatments is generally referred as targeted therapy (distinct from classical chemotherapy) is always administered together with traditional chemotherapeutic agents in cancer treatment regimen. Furthermore, in addition to the combined and targeted chemotherapy, some of the newer strategy have also been explored particularly the use of light (phototherapy) and heat 
(hyperthermia) techniques. In some of the strategy where, the drugs that converted to cytotoxic agent only upon the exposure of light is called photo chemotherapy or photodynamic therapy [6].

\section{Treatment strategies}

Now a day, many strategies have been adapted to administered chemotherapeutic drugs. Chemotherapeutic drugs may be used with a curative purpose or it may be aimed to prong life.

a) Combined chemotherapy is the one kinds of treatment strategy where more one type of therapy can be adopted at a time to treat cancer, such as radiation therapy, surgery and/ or hypertheremia. However, induction chemotherapy is used for the first time treatment of cancer with anticancer drug [7].

b) Consolidation chemotherapy is generally given after remission in order to prolong the overall disease-free time and improve overall survival [8].

c) Intensification chemotherapy is identical to consolidation therapy but a different drug than induction therapy is used.

d) In combined chemotherapy, different dugs are having different kinds of mechanism of action and their side effects. The most advantage of combined chemotherapy is to minimize the chances of development of resistance to any one the drug. Also the drugs can be administered at lower dose with minimal side effects and toxicity

e) .Neoadjuvant chemotherapy is used prior to a local treatment such as surgery, and is meant to shrink the primary tumor [9]. It is also used to a condition where a high risk of micrometastatic disease observes.

f) This therapy (Neoadjuvant chemotherapy) can be used where there is a little a chance or evidence of cancer present and also there is risk of recurrence. It is also beneficial to kill the cancerous cells that have proliferated to other part of the body [10].

g) Maintenance chemotherapy is one where a repeated low-dose is used to treat for prolong remission.

h) Salvage chemotherapy is useful to simply decrease tumor load and increase life expectancy [11] (Table 1).

Table 1: Common combination chemotherapeutic regimen [1].

\begin{tabular}{|c|c|c|}
\hline \multirow{2}{*}{ Cancer Type } & Drugs & Acronym \\
\hline \multirow{2}{*}{ Hodgkin's Disease } & Mustine, Vincristine, Procarbazine, Prednisolone & MOPP \\
& Doxorubicine, Bleomycine, Vinblastine, Dacarbazine & ABVD \\
\cline { 2 - 3 } & Cyclophsphamide, Methotraxate, 5-Fluorouracil & CMF \\
\hline \multirow{2}{*}{ Breast Cancer } & Doxorubicine, Cyclophsphamide & AC \\
\hline Germ Cell Tumor & Bleomycin, Etopside, Cisplatin & BEP \\
\hline Stomach Cancer & Epirubicine, Capecetabine, Cisplatin & EXC \\
\hline Bladder Cancer & Epirubicine, Cisplatin, 5- Fluorouracil & ECF \\
\hline Non-Hodgkin's Lymphoma & Methotraxate, Vincristine, Doxorubicine, Cisplatin & MVAC \\
\hline Lung Cancer & Cyclophsphamide, Doxorubicine, Vincristine, Prednisolone & CHOP \\
\hline Colorectal Cancer & 5- Fluorouracil, Folonic acid, Oxaliplatin & CAV \\
\hline
\end{tabular}

All the above chemotherapeutic regimens are given to the patient that may be capable of withstand the treatment. A patient can be able to continue the chemotherapy or whether the dose reduction is needed, for that a performance status is always used as a measure. Because less cell death is observed in tumor with each treatment, doses repetitions are required to reduce the size of the tumor. Current chemotherapy regimens are used to treat in cyclic manners, with the duration and frequency of treatments limited by toxicity to the patient [12].

\section{Cytotoxic agents and targeted therapy}

Targeted therapies are known to be a relatively new approach for cancer treatment, and the therapy significantly overcome many of the issues observed during the use of traditional anticancer drugs [13]. The intense toxicity observed with the administration of anticancer drugs is because of the cytotoxic agent that targets non-specific cell. They can inhibit or kill any rapidly growing or developing cell, tumor or normal. Targeted therapies are directly involved to affect cellular proteins, which are responsible to produce abnormal cell growth [14]. This shows that there is a need of the high dose to cancer cells with relatively low dose to others normal cells. Different type of cancer can be treated by the use of specific type of proteins or even on a patient basis under targeted therapies. Moreover, the side effects observed are relatively less as compare to the traditional anticancer drugs. Initially, the target therapies were supposed to be only selective for one protein. However, now it is quite clear that one drug can bind in a specific range of 
protein target [15]. An example target for targeted therapy is the protein produced by the Philadelphia chromosome, a genetic lesion found commonly in chronic myelomonocytic leukemia. This fusion protein has enzyme activity that can be inhibited by imatinib a small molecule drug [16].

\section{Chemotherapy Treatment Strategy Using Hyperthermia.}

In traditional chemotherapy, there is a major drawback of the lack of selectivity, leads to various side- effects, such as alopecia (hair loss), blood disorder, fatigue, nausea and vomiting. So, there is a need to explore other treatment strategy where application of heat (Hyperthermia) is accompanied together with other chemotherapies in order to improve treatment selectivity, reduce recurrence and improve the quality of life of patients. It has been observed that surgical removal of solid tumor generally fails in total remission and therefore a combination therapy must be accompanied by anticancer drugs with radiotherapy or hyperthermia or targeted therapy etc. One new approach, which may achieve these goals, is to the use of hyperthermia technique along with other mode of chemotherapy. In the hyperthermia process a fractionated or continued dose is delivered at the target site that can increase the sensitivity of tumor to chemotherapy, radiotherapy, immunotherapy and immune-based strategies [17]. However, this kind of new approach where the successful application of hyperthermia (where heat is applied only at the tumor site) together with other chemotherapeutics has led to renewed interest in the field of modern chemotherapy. The major objective of hyperthermia is to make tumor cells more sensitive towards the therapeutic agents and facilitate drug release from thermo responsive nano carriers (usually below $43^{\circ} \mathrm{C}$, referred to as mild hyperthermia) or, at higher temperatures, directly inducing necrosis (above $43^{\circ} \mathrm{C}$, referred to as thermal ablation) [18]. Furthermore, cancer cells are more sensitive towards thermal environment than normal tissues between $42-45^{\circ} \mathrm{C}$ with a directly proportional relationship between tissue death and the temperature or exposure time. The mechanism of action of hyperthermia is accompanied by various way where the cells or tissues leading to an enhanced antitumor response. In general, hyperthermia inhibits cell functions, increase permeability and modify fluidity, disrupt stability and shape of cell membrane, impending trans membrane transport proteins and cell surface receptors [19].

Transfer of heat, away from tumor cells is directly proportional to the rate and volume of tumor perfusion [20], and assuming that the process is more efficient in malignant tissue compared to healthy tissue [21], enforcing selectivity of hyperthermia. However, the significant effects of hyperthermia are supposed to be on protein as they undergo denaturation and precipitation at temperature $>40^{\circ} \mathrm{C}$. Although the effects on lipids are mostly reversible, but the effect on DNA where, double strand break and effect produced is substantial and non-reversible. This basically inhibits many cellular processes such as cell cycle arrest, replication and synthesis of DNA and alters protein synthesis, leading to inhibition of cell proliferation and death $[22,23]$. There are a number of other strategies that oncologists can use to regulate chemotherapy.

\section{Targeted Therapy}

Targeted therapies specifically target a protein or other molecules and have the benefit of reducing chemo side effects.

\section{Hormone Therapy}

Activated hormone receptors change the way that a gene is expressed. That means these receptors change the way that the gene behaves, often stimulating cell growth. Hormone-sensitive cancer cells have extra hormone receptors [24].

\section{Dose-Dense Chemotherapy}

Dose-dense chemotherapy treatment refers to treatments that are timed to occur close together. If conventionally scheduled chemotherapy treatments are once every three weeks, the dosedense schedule might be once every two weeks. This strategy is used for more advanced cancers that are starting to spread [25].

\section{Combined Modality Chemotherapy}

Combined modality simply means using more than one type of therapy to treat the cancer. If the cancer is aggressive and at stage 3 , the treatment includes surgery, chemotherapy, radiation, and then a year of Herceptin.

\section{Palliative Chemotherapy}

Palliative therapy is treatment that is given to improve quality of life. The purpose of palliative care is to ease pain and reduce the tumor size to improve organ function, rather than to eliminate the cancer altogether. While it is often thought of as a long-term end-of-life strategy to provide comfort, palliative care can also be a temporary addition to the treatment strategy at any point in the process to address a quality-of-life issue [26].

\section{Photodynamic therapy (PDT)}

It is a ternary treatment for cancer involving a photo sensitizer, tissue oxygen, and light (often using lasers. Photodynamic therapy can be used as treatment for basal cell carcinoma (BCC) or lung cancer; PDT can also be useful in removing traces of malignant tissue after surgical removal of large tumors [27].

\section{Cancer immunotherapy}

Cancer immunotherapy refers to a diverse set of therapeutic strategies designed to induce the patient's own immune system to fight the tumor [28]. Contemporary methods for generating an immune response against tumors include intravesical BCG immunotherapy for superficial bladder cancer, and use of interferon and other cytokines to induce an immune response in renal cell carcinoma and melanoma patients.

\section{Conclusion}

There are so many types of treatments that this is not an exhaustive listing of all the chemotherapy strategies available 
to oncologists. Research continues to develop new treatments and more strategies for using existing treatments. Further improvements of this treatment strategy will undoubtedly involve the development of more efficient anticancer drugs. The strategy reported herein, i.e. based on modifying clinically approved drugs certainly holds promise. However, further validation of all this approaches are still needed as authentic strategy also display relevant therapeutic properties under normal conditions and to determine whether it has advantages over the well-established use of chemotherapeutics, some of which are progressing through clinical trials.

\section{Acknowledgment}

The authors thank to Narayan Institute of Pharmacy and Faculty of Pharmaceutical Sciences, Shoolini University BajholSolan H.P. (India) for providing research facilities.

\section{References}

1. Knoepfler PS (2009) Deconstructing stem cell tumorigenicity: a roadmap to safe regenerative medicine. Stem cells 27 (5): 1050-1056.

2. Drusano GL (2004) Antimicrobial pharmacodynamics: critical interactions of' bug and drug. Nat Rev Microbiol 2(4): 289-300.

3. Ferrara N, Kerbel RS (2005) Angiogenesis as a therapeutic target. Nature 438(7070): 967-974.

4. Conklin KA (2000) Dietary antioxidants during cancer chemotherapy: impact on chemotherapeutic effectiveness and development of side effects. Nutr Cancer 37(1): 1-8.

5. Wang S, Placzek WJ, Stebbins JL, Mitra S, Noberini R, et al. (2012) Novel targeted system to deliver chemotherapeutic drugs to EphA2expressing cancer cells. J Med Chem 55(5): 2427-2436.

6. J Sanchez-Barcelo E, D Mediavilla M (2014) Recent patents on light based therapies: photodynamic therapy, photothermal therapy and photoimmunotherapy. Recent Pat Endocr Metab Immune Drug Discov 8(1): 1-8.

7. Adam R, Pascal G, Castaing D, Azoulay D, Delvart V, et al. (2004) Tumor progression while on chemotherapy: a contraindication to liver resection for multiple colorectal metastases?. Ann Surg 240(6): 10521061.

8. Einhorn LH, Crawford J, Birch R, Omura G, Johnson DH, et al. (1988) Cisplatin plus etoposide consolidation following cyclophosphamide, doxorubicin, and vincristine in limited small-cell lung cancer. J Clin Oncol 6(3): 451-456.

9. Buzdar AU, Singletary SE, Theriault RL, Booser DJ, Valero V, et al. (1999) Prospective evaluation of paclitaxel versus combination chemotherapy with fluorouracil, doxorubicin, and cyclophosphamide as neoadjuvant therapy in patients with operable breast cancer. J Clin Oncol 17(11): 3412-3417.

10. Peters III WA, Liu PY, Barrett RJ, Stock RJ, Monk BJ, et al. (2000) Concurrent chemotherapy and pelvic radiation therapy compared with pelvic radiation therapy alone as adjuvant therapy after radical surgery in high-risk early-stage cancer of the cervix. J Clin Oncol 18(8): 1606-1613.

11. Fishman PN, Pond GR, Moore MJ, Oza A, Burkes RL, et al. (2006) Natural history and chemotherapy effectiveness for advanced adenocarcinoma of the small bowel: a retrospective review of 113 cases. American J Clin Oncol 29(3): 225-231.
12. Green MR, Manikhas GM, Orlov S, Afanasyev B, Makhson AM, et al. (2006) Abraxane $\AA$, a novel Cremophor $\AA$-free, albumin-bound particle form of paclitaxel for the treatment of advanced non-small-cell lung cancer. Ann Oncol 17(8): 1263-1268.

13. Cho K, Wang XU, Nie S, Shin DM (2008) Therapeutic nanoparticles for drug delivery in cancer. Clin Cancer Res 14(5): 1310-1316.

14. Peer D, Karp JM, Hong S, Farokhzad OC, Margalit R, et al. (2007) Nanocarriers as an emerging platform for cancer therapy. Nat Nanotechnol 2(12): 751-760.

15. Higueruelo AP, Jubb H, Blundell TL (2013) Protein-protein interactions as druggable targets: recent technological advances. Curr Opin Pharmacol 13(5): 791-796.

16. Fabian MA, Biggs WH, Treiber DK, Atteridge CE, Azimioara MD, et al. (2005) A small molecule-kinase interaction map for clinical kinase inhibitors. Nat Biotechnol 23(3): 329-336.

17. Needham D, Dewhirst MW (2001) The development and testing of a new temperature-sensitive drug delivery system for the treatment of solid tumors. Adv Drug Deliv Rev 53(3): 285-305.

18. Zhang Z, Wang J, Nie X, Wen T, Ji Y, et al. (2014) Near infrared laserinduced targeted cancer therapy using thermoresponsive polymer encapsulated gold nanorods. J Am Chem Soc 136(20): 7317-7326.

19. Alvarez-Berríos MP, Castillo A, Mendéz J, Soto O, Rinaldi C, et al. (2013) Hyperthermia potentiation of cisplatin by magnetic nanoparticle heaters is correlated with an increase in cell membrane fluidity. Int J Nanomedicine 8: 1003-1013.

20. Khaled AR, Vafai K (2003) The role of porous media in modeling flow and heat transfer in biological tissues. Int J Heat Mass Transf 46 (26): 4989-5003.

21. Jori G (1996) Tumour photosensitizers: approaches to enhance the selectivity and efficiency of photodynamic therapy. J Photochem Photobiol B 36(2): 87-93.

22. Evan GI, Vousden KH (2001) Proliferation, cell cycle and apoptosis in cancer. Nature 411(6835): 342-348.

23. Clavel CM, Nowak-Sliwinska P, Păunescu E, Dyson PJ (2015) Thermoresponsive fluorinated small-molecule drugs: a new concept for efficient localized chemotherapy. Med Chem Comm 6(12): 20542062.

24. Feldman BJ, Feldman D (2001) The development of androgenindependent prostate cancer. Nat Rev Cancer 1(1): 34-45.

25. Del Mastro L, De Placido S, Bruzzi P, De Laurentiis M, Boni C, et al. (2015) Fluorouracil and dose-dense chemotherapy in adjuvant treatment of patients with early-stage breast cancer: an open-label, $2 \times 2$ factorial, randomised phase 3 trial. The Lancet 385(9980): 1863-1872.

26. Alberts SR, Horvath WL, Sternfeld WC, Goldberg RM, Mahoney MR, et al. (2005) Oxaliplatin, fluorouracil, and leucovorin for patients with unresectable liver-only metastases from colorectal cancer: a North Central Cancer Treatment Group phase II study. J Clin Oncol 23(36): 9243-9249.

27. Brown SB, Brown EA, Walker I (2004) The present and future role of photodynamic therapy in cancer treatment. Lancet Oncol 5(8): 497508.

28. Curiel TJ (2007) Tregs and rethinking cancer immunotherapy. J Clin Invest 117(5): 1167-1174. 

CC (1) This work is licensed under Creative

DOI: 10.19080/OAJT.2018.02.555600
Your next submission with Juniper Publishers

will reach you the below assets

- Quality Editorial service

- Swift Peer Review

- Reprints availability

- E-prints Service

- Manuscript Podcast for convenient understanding

- Global attainment for your research

- Manuscript accessibility in different formats

( Pdf, E-pub, Full Text, Audio)

- Unceasing customer service

Track the below URL for one-step submission

https://juniperpublishers.com/online-submission.php 